\title{
An Investigation of Ethiopian Journalists' Ethical Practices with Respect to Their Own Editorial Policies: Broadcast Media Journalists in Focus
}

\section{Muluken Asegidew Chekol, Dilla University, Ethiopia}

\begin{abstract}
Constructing arguments on the level of journalism ethics violations by identifying the main factors influences journalists to work against their professional interest, and evaluating editorial policy documents and editorial meeting were the basic objectives achieved. Methodological wise, both quantitative and qualitative approaches were employed. About 117 journalists were involved. There are significant, if not critical, media ethics violations by Ethiopian broadcast media journalists. Both in cash and in kind journalist collect benefits from news sources and news makers. In return, they offer positive and success story coverage. Government and media have symbiotic relationships, but in Ethiopia, it is more than thatgovernment officials influence the media. Public official pressures, amateurism and burden of living cost are main factor influence journalists to act unethically. The media editorial policies are not clear and accessible. Media fired and punish in fine "unethical" journalists.
\end{abstract}

Keywords: Ethiopian journalists, ethical practices, editorial policies. 


\section{Introduction}

Media are required to develop ethical guidelines to prevent their staffs from any deliberate and unconscious "violation of the guidelines as a serious offense that may lead to disciplinary action, potentially including dismissal, subject to the terms of any applicable collective bargaining agreement" (The New York Times Handbook of Ethical Journalism, 2004). The fundamental purpose of developing media ethical guidelines is to protect the impartiality and neutrality of media and the integrity of its report. Journalists who plagiarize or who knowingly or recklessly provide false information for publication betray the media fundamental pact which is seldom tolerated by media audiences.

There are situations where level of media malpractices and ethical conducts violations increases, such as, personal relations with news sources; accepting hospitality from sources; covering business-financial, technology, voting and campaigns. Some, if not all, institutions, organizations, companies, agencies and even individuals provide gifts and awards to journalist who did positive coverage to them. The gifts and awards may not have clear justification as to why the media people deserve to own it.

Studding journalism malpractice such as violation of professional ethics need a thorough look and investigation into the pushing and pulling factors and ways of violation. Since it is both breach of disciplines and crime, its effect is twofold- it is a suicide to the media industry itself and massacre on citizens' balanced, fair and objective information accessing rights. So it should be closely monitored by press council; it should be guided by professional ethical principles; and it should be evaluated by academicians and researchers.

Mendes (2013) noticed that raising the professional standards of journalism profession involves developing an ethics management system for the media that includes raising journalist's awareness of the ethical challenges they face in the exercise of their professions through the adoption of a robust code of ethics. He (2013, p. 8) argued that "This code should meet universal standards at a global level and be implemented at a local level." But, this is not yet the case in many developing countries. According to the Centre for International Media Ethics' (CIME) Media Ethics Survey 2011 in Asia, Africa, Latin America and Europe only half of the media outlets do have a code of ethics in place (CIME, 2011; cited in Mendes, 2013). 
Ethiopian Five Years Growth and Transformation Plans (GTP) seems the main pulling factors to Ethiopian journalists in compromising their ethics. There are a number of projects here and there and project managers and concerned public officials influence the media heavily to sell those projects using the media, specially the broadcast media. This is assumed as the basic intersection point between the media and the one who is hungry for positive coverage and which is pretty difficult for journalists to stick with professional ethical principles and editorial policies.

\section{Objective of the Study}

The main objective of this study is investigating Ethiopian broadcast media journalists' practices of media ethics and media editorial policies and identifying factors which deceive journalists to violate their editorial policies. On top of that the study aims to examine the gaps between ethical principles and ethical practices, hence, able to determine the level of journalism professional ethic violation in Ethiopian broadcast media.

\section{Research Questions}

- What is the state of Ethiopian media editorial policy document accessible?

- What are the factors that influence Ethiopian broadcast journalists to violate their professional ethics and editorial policies?

- Where is Ethiopian journalists' level of journalism ethics violation? Is it at its lower, significant or critical level of violation?

\section{Scope of the Study}

The main focus of the study is Ethiopian broadcast media; for which purpose six broadcast media were selected- four from government and two from non government. Print media in general, community radio, other FM radio, news agencies, and international media in general are not part of the study. Furthermore, it is limited only to reporters and editors, who have direct impact rather than limited and indirect impact on media ethics practices.

\section{Methodology}

\section{Methods of the Study}

The research employs both quantitative and qualitative research approaches. The quantitative approach helped to look into facts collected by distributing questionnaires. In addition, to 
compliment the quantitative data, interviews were conducted with law department expert, discipline officer, media development director, senior editors, and vice manages. Furthermore, document observation had been employed. The documents are media editorial policies, media proclamations, and related media code of Ethics.

\section{Sampling Techniques and Data Collecting Tools}

The subject of the study is Ethiopian broadcast media journalists who are on duty. The media were selected, purposively, based on their high area and audiences' coverage, as such; the following six broadcast media were identified. - Ethiopian Broadcasting Corporation (EBC), - Amahara Mass Media Agency (AMMA),

- Oromiya Radio and Television Agency (ORTVA),

- South Radio and Television Agency (SRTVA), plus,

- Fana Broadcasting Corporate (FBC) Share Company and

- Sheger FM 102. P.L.C

From the selected media 111 out of the total 1066 journalists participated in filling the questionnaires- 20 of 196 from AMMA, 24 of 342 from EBC, 20 of 153 from FBC, 9 of 22 from Sheger FM, 16 of 90 from SRTVA, and 22 of 263 from ORTVA. The population sizes ranges from 22 journalists in Sheger FM to 342 in EBC. Technically, censes sampling could be implemented in some of the selected media, but, it was impossible to address all journalists, because of their working nature- a portion of journalists travel to field and some are busy at studio production work. Interview held with sex media people who hold various positions in the selected media.

\section{Application of Results}

The research can serve as a warning bell to media industry governing and running bodies; it can be Ethiopian government, Ethiopian Broadcasting Authority, Ethiopian ombudsman, Ethiopian anti-corruption organizations, civil organizations and others would listen to the warning bell. Specially, the government may take the case as rent-seeking practice and play key role to tackle media ethics violations, because, it is one of the hurdles of nation building process. 


\section{An Over-View of Media Ethics}

Any law, including the media, usually is formulated by a certain government entity. In the case of Ethiopian, the power of making laws is resigned in the hands of the legislative body. But sorting out various ethical behaviors of any profession is not under the sole control of any government body. Institutions, organizations, agencies and usually professional associations have been doing great job in setting out code of ethics. As such members of the Society of Professional Journalists as mentioned by Moore \& Murray (2008) emphasized on the following journalists' ethical practices:

Members of the Society of Professional Journalists believe that public enlightenment is the forerunner of justice and the foundation of democracy. The duty of the journalist is to further those ends by seeking truth and providing a fair and comprehensive account of events and issues. Conscientious journalists from all media and specialties strive to serve the public with thoroughness and honesty.

Professional integrity is the cornerstone of a journalist's credibility (p, 746).

Discussions surrounding contemporary ethics codes have focused on three major areas of concern: the content of ethics codes; the amount reporters and editors consult them; and, news managers' seeming inability to formalise penalties for individuals who do not abide by the codes.

\section{The Content of Media Ethics Codes}

The Society of Professional Journalists' journalism codes of ethics are presented well and in detail. Moore and Murray (2008) attached these codes of ethics as appendix in their book entitled 'Media Law and Ethics'.

Seek Truth and Report It: Professional electronic journalists should pursue truth aggressively and present the news accurately, in context, and as completely as possible

Minimize Harm: Ethical journalists treat sources, subjects and colleagues as human beings deserving of respect.

Act Independently: Journalists should be free of obligation to any interest other than the public's right to know.

Be Accountable: Journalists are accountable to their readers, listeners, viewers and each other. Journalists should: 
Public Trust: Professional electronic journalists should recognize that their first obligation is to the public. They should:

Fairness: Professional electronic journalists should present the news fairly and impartially, placing primary value on significance and relevance.

Integrity: Professional electronic journalists should present the news with integrity and decency, avoiding real or perceived conflicts of interest, and respect the dignity and intelligence of the audience as well as the subjects of news.

Independence: Professional electronic journalists should defend the independence of all journalists from those seeking influence or control over news content.

Accountability: Professional electronic journalists should recognize that they are accountable for their actions to the public, the profession, and themselves.

\section{Journalists' Practices of Ethics}

Dugan, (2008; p.3) noted that "Journalists ... are able to undermine the credibility of the profession by not following ethical practices. But journalists affiliated with news organizations are watched by an entire staff of ethical police: editors. A news organization needs journalists to follow ethical guidelines to maintain its credibility, which is directly related to its financial success." Peck \& Reel (2013, p. 4) also stated that "Each professional [reports and editors] is the architect of his or her own credibility, and each individual's credibility is key to establishing the credibility of the media as a whole." Area School Groups (n. d, p. 10) explained that "[ethics] involves the way reporters and editors pursue stories, the feeling that editorial viewpoints drive news content, placement and headlines. This category also focuses on the methodology of reporting, ranging from paparazzi photography to insensitivity to victims."

Scholars like Joan (2014) expanded the responsibility of upholding media ethics all media staffs. He argued that "Whether you are a reporter, editor, photographer/videographer, graphic designer or public relations specialist, virtually every choice you make tests your ethics and values. Every story, image, video or promotional effort carries consequences." But unarguably, Editors in various levels have the responsibility of supervising and controlling each publication. Excerpt of Ethiopia Press Freedom Proclamation explains this.

The mandate of the editor in chief designated by the publisher encompasses the power to supervise the publication of the periodical and to determine the contents 
thereof in such a way that nothing may be printed therein against his will. Any practice or agreement that restricts this power shall be null and void. The editor-inchief ... shall have legal responsibility for the content of the mass media outlet and shall... have the power to veto the publication of any material (Pro. NO. 590/2008, Article 6(1).

\section{Media Ethics and law Violations and Penalties in Ethiopia}

One can asks that what kind of punishment can be imposed on journalists who violated media ethics and editorial policy; who is entitled to punish violators? Who may put forward violations of media ethics and how measures can be taken on violators? Such questions answered on Ethiopian Press Freedom Proclamation- Proclamation No. 590/2008 and Ethiopian Broadcasting Proclamation- Proclamation No. 178/1999. The first and minimum step that media requested to take, in time of defamation, is publicizing or airing correction - serving the right of reply to complaints free of charge. If not, "Any person whose right of reply is refused may apply to the court to compel the chief editor of the periodical or program to insert the reply in the press. The court may ... render [chief editor] liable to punishment" Article 40(1 - 4).

The following excerpt article from Ethiopian Press Freedom Proclamation- Proclamation No. 590/2008 explains who is the responsible body to punish media and what kind of punishments can be impose.

In an action for defamation through the mass media the court may award, having regard to the seriousness of the moral damage, compensation up to 1000,000 birr having regard to the seriousness of the damage (Article 41(2). Any publisher of a periodical or broadcaster who ... violates the obligations provided under article 10 , [failed to imprint and gratuitous copies] shall be punished with a fine up to 15,000 Birr. Article 45(2)

It is clear that the regular court, which is part of the government, has the power to punish 'violent' media institutions and journalists. The fine punishment ranges from 10,000 to 100,000 Birr based on the kind of article violated. In addition, the court may issue compensation upto1, 000, 000 Birr and imprisonment. Ethiopian Broadcasting

Proclamation- Proclamation No. 178/1999- recognizes Ethiopia Broadcast Agency (EBA) to govern Ethiopian media. It is administered by government elected board 
members. The board entitled with the power to "direct and control the activities of the agency; prepare and submit to the government the general policy of broadcasting service and ensure its implementation when approved; investigate and decide on the complaints of broadcasting service licensees and the public (Article 10).

Ethiopian Broadcasting Proclamation- Proclamation No. 178/1999- Article 27 deals with programming principles which are highly connected with journalism ethics.

Article 27 (1) Every transmitted programs shall, by reflecting varying view points, serve the public at" large through balanced presentations.

Article 27 (2) Every transmitted program shall ascertain the accuracy of its source and content.

Article 27 (3) Every news shall be accurate, balanced and free from partiality.

Article 27 (4) Any transmitted programs shall not:

(a) Violate the dignity and liberty of mankind, the rules of good behaviour or undermine the belief of others;

(b) Commit a criminal offense against the security of the State, the constitutionally established Governmental Administration or the Defense Force of the country;

(c) Maliciously accuse or defame individuals, Nation Nationalities, people or organizations;

(d) Instigate dissension among nationalities or cause to initiate dissension among peoples; (e) Incite war.

In addition, the proclamation tries to clarify the boundary between commercials and noncommercial programs. Article 30(1) read as "An advertisement shall be transmitted in a manner that clearly differentiates it from other programmes. It shall not also affect the contents of other programmes." And article 33(1) also stated that "The content and time table of sponsored programme shall not fall under the influence of the sponsor. Especially, the sponsored programme shall not agitate the sale or hire of the sponsor's products or services." The broadcast proclamation is more detail and softer than the free press proclamation. Penalty is more based on the content of the broadcast media program and way of presentation. Fine punishment ranges from 5,000 to 50,000 Birr and it is easier compare to the fine punishment 
stated in the free press proclamation (10,000 to 100,000 Birr). Concerning imprisonment, a range of six months to five years is stated based on the kind of article get violated.

\section{Factors Influencing Journalists to Violate Ethics}

Committee of Concerned Journalists (2000, p 63-79) pointed out the following factors that influences journalists' ethical practices at work.

Conflicts of interest: Conflicts of interest are one of many triggers for the need to make ethical choices. The primary interest of the journalist should be to inform the public, however, competing goals - money, fame, associations, ideas - might well lead to a conflict.

Decision Making: Each individual working in the mass media needs to consider all of those whom journalists' decisions affect, all the time. In turn, they affect (or attempt to affect) what the media to say and to do.

Consequences: Suppose your employer tells you to do something that seems immoral or unethical to you. After you've thought about it your response may well depend upon how easy it would be to find a new job.

Pressures: Deliberate pressure, from those with power like government and political parties, affects advertising, public relations, and creative personnel in all media fields who need to have an audience.

Economic and Individual Autonomy: Economic pressures on individual autonomy are increasingly common in media conglomerates, where top management may have little familiarity with traditions that historically have been important to their media subsidiaries.

\section{Media Ethics Theories}

Ethics and moral philosophical concepts and theories foundation are traced back to ancient time of Socrates, Plato and Aristotle. Here the focus is on Aristotle's Doctrine of the Mean (virtue ethics) and Kant's Categorical Imperative (duty ethics) and their connection with journalism principles and ethics.

\section{Aristotle's Doctrine of the Mean (Virtue Ethics)}

Aristotle usually associated with the discussion of ethics in general and media ethics in particular. As such, “Journalism and media ethics texts commonly invoke Aristotle's Golden Mean as a principal ethical theory that models such journalistic values as balance, fairness, and proportion" (Cunningham, 1999). 
The general concept of Aristotle's 'golden mean' theory suggests that the most virtuous course of action an individual can take in any ethical situation is one which sits at the midpoint between excess and deficiency. As Aristotle, the two extreme tips of any one's argument, point of discussion and even truth couldn't serve the interest of the majority. Cunningham (1999) explained that when the Aristotle's golden mean narrow down to the media ethics scope, its implication may be that the majority of media audience interests have been served if media produce balanced, fair and moderate reports. The following paragraph linked Aristotle's virtue ethics with contemporary journalism principles and media ethical practices:

Modern journalistic balance and fairness are founded on this [virtue ethics] principle . . . While minute-for-minute equality in broadcasting can be a flawed application of the golden mean, Aristotle's principle is valuable to media people when making moral decisions, as long as they do not abdicate their power of reason to embrace formulaic tit-for-tat measurable equality . . . It takes a sharp mind to sort through issues of balance and fairness. (Vivian \& Peter, 1997, pp. 370- 371 cited in Cunningham, 1999, p. 2)

One can asks that who determines as some decision and selection is right "Virtue". Cunningham (1999, p. 5) stated that "Virtue is the informed choice of a morally developed person whose cognitive apparatus and emotional status are in good working order." As such, journalists are the one who will select, deiced and do the right thing based on rational reasoning. Cunningham (1999, P. 7) stressed that when the journalist undertakes ethical choices, those selfsame work practices and standards that define his role as reporter, commentator, or editor are enhanced (or diminished, in the case of unethical choices). Fair, honest, and courageous reporting that reflects complex social realities and also respects the vulnerabilities of others is more likely to result in a story that is superior to any lacking those same qualities.

\section{Kant's Categorical Imperative (Duty-Based Ethics)/ Deontological Ethics}

Kant's duty based ethics lays on fulfilling assigned duties whatever the consequences may be aftermath of the actions someone takes. As duty ethics, ethical practice is to mean doing the 'right' action ignoring what the outcome may be bad or good. The 'right' action is decided by doers' morality and conscious level. Duty ethics listed out the following moral rules which tried to justify why someone should make his/her duty:

- Do it because it's the right thing to do. 
- Don't do wrong things.

- Avoid them [actions/ duties] because they are wrong.

Someone who follows duty-based ethics should do the right thing, even if that produces more harm (or less good) than doing the wrong thing. For example, Kant thought that it would be wrong to tell a lie in order to save a friend from a murderer (Deontological Ethics Review from www.BBC.co/UK).

Duty Based Ethics clearly coincides with some of the basic principles and ethics of journalists'- telling the truth and accuracy. Journalists should tell the truth and make their report accurate whatever the consequences will be. But, this is also against the other journalists' ethics- minimizing impact.

\section{Media Ethics Practices in Ethiopian Broadcast Media}

The selected media ethical principles and Editorial Policies documents have been examined. Reporters and editors media ethics practices have been checked through questionnaires and interview. The results and findings of questionnaires responses and interviewees presented and discussed below.

\section{Ethiopian Broadcast Media Background Information}

\section{Amahara Mass Media Agency (AMMA)}

Amhara Mass Media Agency has started broadcasting since 1999 on Ethiopia Television channel. It has established as self standing channel in 2013. But, like others Ethiopian regional states' media, it has still one hour television program on EBC each day. There are 196 journalists on duty- out of it 103 of them are working on the television channel where as 93 of them assigned to the radio programming section under the same roof.

AMMA has senior and experienced journalists who have the exposure for media ethics trainings. Although, only 30 percent of them are from journalism and communication field of study; the intense trainings assumed to fill their media ethics understanding gaps. But, whatever trainings can be offered to on duty journalists, in a medium where 70 percent journalists are non-journalism and communication degree holders, there is no doubt that such journalists show gaps in practicing their ethics. 
About 95 percent are degree graduates and 75 percent of them become journalists, because, they like to be so. This can be taken as success in a country of Sub-Saharan Africa. But, it is worrisome that the broadcast media are filled with journalists who did not take significant number of journalism courses in regular bases. This gap is visible on the responses they provide to the research questionnaire. For instance, 25 percent of the AMMA respondents did not read their editorial policy at all.

\section{Ethiopia Broadcast Corporation}

Ethiopia Broadcast Corporation (previously ETV) established in 1963. From 2009 to 2014 it was renamed Ethiopia Radio and Television Agency (ERTA), incorporating Ethiopia national radio and FM Addis 97.1. Starting from 2014 ERTA transform to the level of corporation and named as Ethiopia Broadcast Corporation (EBC). Currently, there are about 342 journalists on duty who are working on the television channel, national radio and FM Addis 97.1. EBC journalists are the highest paid government broadcast media journalists. The most senior one can make 14,000 birr monthly salary which can be taken as one of the most top paid professions in Ethiopia. They pass through range of experiences. Senior reporters and editors/ producers account 91 percent of the questionnaire respondents. About 66 percent of the journalists have above five years reporting experiences and also 41 percent of them graduated in journalism and communication. The rest 59 percent are from other disciplines which can be taken as weak side of the media industry.

Degree holders are about 79 percent where masters account only 16 percent. First degree seems the minimum requirement to join $\mathrm{EBC}$, although, a significant number of them leave the corporation after three or four year services. EBC journalists get many opportunities of trainings on media ethics. Only one-third of them become journalist, because, they like to be journalist. The rest 75 percent join EBC aiming economical benefits (better salary and per dim,) and because they are appointed by government.

\section{Fana Broadcasting Corporate}

It was named as radio Fana when it was established in 1999. Now it's upgraded in to Broadcasting Corporate level since 2011. Fana Broadcasting Corporate (FBC) is a company incorporating Fana national radio, Fana FM stations and it plans to run television channel in 
2017. The corporate already own the first media complex building at Addis Ababa around Tikur Ambessa district. FBC is an affiliated medium to Ethiopian People Revolutionary Democratic Front (EPRDF); and it promotes and defends government policies and strategies. But, it is relatively the strongest medium to challenge government maladministration and poor implementation of policies and strategies.

FBC has 153 journalists on duty at the head office, Addis Ababa.

FBC 95 percent journalists are senior reporters, editors and producers. Nearly 65 percent of journalists have been serving four to eight years in average; although, it is indicated that only 10 percent of journalists have more than eleven service years in FBC. This indicates that the most experienced journalists leave the media and it may have negative impacts on FBC if there were free and competitive media in the country.

Nearly half FBC journalists have degree in journalism and communication. Even in FBC which shows a significant progress in hiring graduates of the profession, 55 percent of the journalists are from other field of studies. About 90 percent are degree holders and the rest 10 percent have master degree which can be seen as very good achievement by any standards in a country like Ethiopia. In addition, 90 percent of them get training on media ethics. About 85 percent of the journalists join FBC, because, they like to be journalist, and 95 percent of the journalists have employed through vacancy.

\section{Sheger FM (FM 102.1)}

Sheger FM 102.1 was established in 2005. It is the first private FM radio channel in Ethiopia. It has 22 journalists on duty.

Sheger FM 102.1 senior reporters and editors account 89 percent of journalists. About 55 percent journalists have four to eight years experiences where as 22 percent of them serve more than (11) years in Sheger FM. It seems common problem for all media to retain long serving journalists. Nearly 66 percent journalists are first degree holders; 22 percent are MA and 11 percent are diploma. Journalism and communication degree holder account 33 percent of Sheger FM journalists. About 45 percent of journalists have access to trainings; the rest participated only in a few trainings. All Sheger FM journalists like to be a journalist. About 67 percent hired through vacancy whereas 33 percent join Sheger due to internship, research and other linkages. 


\section{South Radio and Television Agency}

South Ethiopia Peoples, Nations and Nationalities Regional State Radio and Television Agency was established in 2014. It is located in the regional city, Hawassa. This region incorporates more than 50 various languages and cultures. As a result, the regional media used Amharic language which widely spoken as first and second language. At the end of 2015, it has started to use Sidama language for one hour broadcasting program, two days a week. SRTVA has 90 journalists who are working in the television channel, regional radio and Debube FM 100.9.

In SRTVA, 56 percent of journalists are editors and producers and about 50 percent of them have six to ten years of service. Most importantly, about 44 percent are journalism and communication graduates, although, the rest 56 percent are graduates of other social sciences. Educational wise, 75 percent of them are first degree holders and the rest 25 have MA.

Training availability is limited; about 56 percent have got a few trainings on media ethics issues. About 62 percent like to be a journalist; and 69 percent got employment through winning vacancy whereas 31 percent join SRTVA otherwise i.e. through government appointment (19 percent), through relatives and or friendship (12 percent).

\section{Oromiya Radio and Television Agency}

Oromiya Radio and Television Agency (ORTVA) is one of the regional state media in Ethiopia. It is dominantly used Oromiffa language which is widely spoken in the region. Both geography and population wise, the region is the largest one in the country. ORTVA was established in 2009 at the Regional city Adama (Nazret). Around 263 journalists are on duty in ORTVA; some work for the Television channel and some others for Oromiya radio and the rest assigned in the FM radio. ORTVA's journalists have better experiences compare to others; about 59 percent have been serving from six to ten years and 68 percent reach the level of editor. Nearly 54 percent of them are graduates of journalism and communication; and this is a new number better than from other media in Ethiopia. About 95 percent of the journalists have first degree. In addition, about 59 percent get many trainings and the rest 41 percent got at least a few trainings. About 73 percent join the media through vacancy and 68 percent like their profession whereas the government assigned 23 percent journalists. ORTVA's novice journalist earns 2,060 birr salary per month and 228 birr per diem. Editors earn 6,000 birr salary monthly while managers earn 9,000 per month. But, all payments expected to rise in the near future. 


\section{Ethiopian Broadcast Journalists' Concept of Media Ethics}

Under this sub-topic, three basic questions of the questionnaire results presented and discussed. The concept of the questions focus on the availability of editorial document, participation in editorial meetings and the way of disclosing decisions made on editorial meetings. The researcher tried to observe the media libraries to witness the accessibility of editorial documents. The highest portion of respondents, in all the selected media, marks the choice "I read and understand it [their media editorial policy document]". Again, a significant number of journalists have participated many times in editorial meetings. In EBC and FBC, there is a tradition of disclosing editorial meeting decisions for all journalists. But, in AMMA, Sheger FM, and ORTVA, editorial meeting decisions are made clear for few who are only "attached" directly with the issues and decisions. Sheger FM 102.1, (45) percent journalists respond that they have read and understand the editorial document although editorial document was not available in the FM library. In the rest five media, it is check by both library observation and questionnaire responses that editorial documents are available in their library.

Interviewees also tried to explain their media editorial documents. AMMA's legal Affairs expert, Ato Ademasu Kebede, explained how the existing editorial document has been communicated to journalists and editorial meeting held in regular bases; editorial meeting has been conducted twice a day in the agency level and every morning as briefing incorporating all journalists. He added, editorial decisions disclosed to journalists at the briefing and trainings also organized aiming to disseminate the editorial document (Interview, 13, August, 2015).

EBC developed new editorial policy document in 2015. The pocket size editorial policy document is awarded to each journalist. EBC's Discipline Officer, Ato Mengistab G/ Meden, thought that training is ample to EBC journalists from various bodies including the government trainings on its policy and strategies; editorial meeting and morning briefing session are common practices and editorial decisions disclosed for journalists who are directly attached to the decision, (Interview, 20, December 2015).

FBC has well organized library; and the editorial policy is one of the documents sorted in the library shelf. FBC's Media Development and Study Director, Ato Asefa Ahemed clarified that editorial meetings and briefings are routine job every day; and the decisions made by the 
editorial board disclosed to a few journalists; trainings are available to journalists on various aspects of media and journalism, government policy etc, (Interview, 18, December 2015).

Sheger Fm 102.1 Editor, Ato Yeneneh Kebede, admitted that Sheger is still on progress to compile editorial policy document; editorial meetings have been held each morning and editorial decisions disclosed to all journalists in the FM; there are rare training opportunities on journalism ethics and other issues, (Interview, 15, December 2015).

SRTVA's Vice Manage, Ato Semunegus Sheno announced that novice journalists usually have got training on editorial document before they go for assignments; editorial meetings held weekly in editorial board level and daily involving all reporters in a briefing session. He added that radio section, television section and current affair section has editorial meetings separately once in every working day (Interview, 19, December 2015). ORTVA's Vice Manager, Ato Admasu Damtew in his part explained ORTVA's working culture focusing on the journalist' ethics practices. As the Vice Manager, there are regular editorial meeting once a week at agency level, twice a week in editors' level, and daily briefing including all journalists; editorial decisions disclosed to all journalists at the briefing session; in addition, there are both short and long term trainings on editorial policy, journalism ethics, production techniques, program planning. ORTVA also has a trend of sponsoring journalists' regular further education (Interview, 23, December 2015).

\section{Media Ethics Practices of Ethiopian Broadcast Journalists}

The issues of media ethics are basic in the journalists' work life. "Journalists' own ethical standards can be more strengthening than legal ones. They [media ethics] encourage journalists to examine their motivation, their methods, and their work product" (United States of Department of State, 2010). AMMA's legal section expert asserted that journalists in AMMA are accountable to the public, report fairly and balance issues, rely on truth and accurate information, care to minimize stories' impact on the mass, keep confidentiality and privacy of individual sources. But he has also admitted that there are journalists who have accepted money in the form of per diem, prizes, gifts in kind (e.g. honey) and hospitality from who need positive coverage rather than genuine; furthermore, some journalists present fake sick leaf document, absent from work and assignments, steal achieve records and make physical fight with colleagues in office. 
AMMA's legal expert pointed out some of the punishments taken against journalists following their violation of journalism ethics and editorial policy. These are:

- Journalists get fired from AMMA

- Six journalists fee their one month salary and lower from position

- Written warnings were offered to five journalists and also denied from promotion

- Some others refund per diems from sources and return gifts

(Interview, 13 August 2015)

EBC's Discipline Officer mentioned that journalism ethics violation is a reality in EBC. He has disclosed a few acts of unethical behaviors of journalists there, such as journalists' conflict of interest and taking double per-diem from some NGOs and government organizations. He added that there are allegations and rumors that some journalists do engaged in many unethical practices, such as, establishing private media promotion enterprises, get hired in other institutions, accepting bribe from investors in exchange to broadcast adverting like program on the name of development support program and etc. But as he said, many of these allegations have not been proofed because of lack of evidences and no punishment taken on journalist (Interview, 20 December 2015). FBC's Director for Media Development and Study general assessment of FBC's journalists' ethics practices is good. As the director, there is no significant violations of media working ethics in FBC, although, he admitted that journalists and the media itself take accepting per diems from both government and private institutions and NGOs as norm. The Director stated that FBC did not face any defamation charge. But the media it has taken punishment against its journalists, as such, a journalist get fired for accepting money from sources (Interview, 18 December 2015). As to Sheger FM's editor, Ato Yeneneh Kebede, keeping sources privacy was the most respected journalism ethic in Sheger FM. The editor pointed that some Sheger FM journalists assigned themselves for covering events without permission. Regarding punishments, he confirmed that three Sheger FM's journalists awarded written warnings (Interview, 15 December 2015). SRTVA's Vice Manager acknowledged that a few journalists in SRTVA have been violating the editorial policy and media ethics. He pointed out the following:

- Some journalists accept per diem from government and private institutions which need positive coverage rather fair, objective and balanced. 
- Some other journalists have been practicing Self-censorship- deliberately ignore government negative stories, decline to challenge officials- simply attending general work reports, acting as messenger and moth-pieces of public relations and communicators, do not check and verify what is planned and really implemented.

- Furthermore they censor themselves for seek of achieving social rewards- getting acceptance and friendly communication with government officials.

- A few journalists had produced and broadcasted advertising like "program", in name of "development progress focus" (where the medium need to prioritize), in exchange of some financial benefits (Interview, 19 December 2015).

ORTVA's, Vice Manager on his side indicated some of ORTVAs' malpractices. He mentioned that main malpractices of journalists:

- A few journalists need to work in line with their political interests. Some show sympathy to government and some other seems stand against the incompact government.

- A few journalists misunderstand public interest and try to satisfy their ego in the name of free journalism and free media.

- Accepting double per-diem from sources is a reality in ORTVA.

He added, ORTVA prefers teaching first than punishments. But, there were some cases where punishments were implemented; very few journalists fee their monthly salary, lowered from position, forced to refund sources' offers. As the vice Manager, the most respected media ethics in ORTVA is keeping the boundary between advertisement and reports, checking facts and verifying information (Interview, 19 December 2015).

Generally many of the interviewees' testimonies are apparently against free, fair and professional journalism practices by any standard of development journalism which Ethiopian government alleged to exercise in government controlled media. There is a mismatch between the media philosophy and media practices on the ground. In development journalism the media serves as a voice of ordinary citizens not the political and economical elites. The media seems hijacked by individuals who can pay, journalists' interest and government officials' influences. 


\section{Factors Affecting Ethiopian Broadcast Journalists' Media Ethics Practices}

AMMA's legal expert argued that living cost, journalists' greedy behaviors and lack of professionalism are pushing factors which deceive journalists to violate their editorial policy and media ethics. On the other hand government officials' pressure, public relations' attractive deal and NGOs' working and payment trends are pulling factors challenge journalists against rules and ethics (Interview, 13 August 2015). EBC's discipline officer believed that EBC's journalists' economical claim answered significantly by doubling their monthly salary in 2015 . He didn't consider lack of salary and per-diem as pushing factor any more to violate media ethics in EBC. Monitoring becomes more tuff and the discipline department has been established to tackle unethical practices, he added (Interview, 20 December 2015). FBC's Media Development and Study Director inter-related the intensity of unethical act of journalists with the existing journalists controlling mechanism of the media in general. FBC has controlling mechanism to address journalists' misbehavior, he argued. But, he didn't deny that some journalists lack professionalism and which reflects on their practices (Interview, 18 December 2015).

Sheger Fm Editor pointed out that lack of journalism knowhow and recklessness as main internal factors that lead journalists to fail to respect media ethics; furthermore, he listed the following as external factors which expose journalists for malpractices:

- University and Colleges curriculum and teaching system

- Influences from employers (media)

- Government officers', private business men's', investors' pressure and

- Living cost influences on journalists (Interview, 15 December 2015).

SRTVA's Vice Manager asserted that the basic factor, which exposes journalists to violate their ethics, is lack of professionalism. He denied the economical claim which most journalists raised as major factor (Interview, 19 December 2015).

ORTVA's Vice Manager in his part pointed out some of the basic factors that push journalists to violate media ethics. These are:

- Philosophical- some journalists reject development journalism rather they need liberal, in his word "neoliberal” which he believes emanates from Universities' curriculum. 
- A few government officials also tried to influence journalists for positive coverage and some journalists lack the courage to refuse.

- Lack of knowledge and expertise of journalism is also fatal problem in Ethiopia.

- Low salary can be a major factor, despite, journalists are one of the highest paid. (Interview, 23 December 2015).

\section{Leveling Ethiopian Broadcast Media Ethics}

It is attempted to level Ethiopian broadcast media ethics through two questions. The first question was list of qualitative leveling and the second was letter grading. The letter grade represents a leveling alike academic scores. Journalists mark one of the leveling choices based on their general assessment of Ethiopian broadcast journalists' ethics practices.

The highest percentage of respondents confirmed that there are significant media ethics violations in their respected medium in general. For instance, in SRTVA, it is found that 56 percent of the respondents showed the existence of critical media ethics violations. In terms of letter grading, in AMMA and in FBC 65 percent respondents; in EBC 50 percent respondents; in Sheger FM 67 percent respondents; in SRTVA 81 percent respondents and in ORTVA 78 percent of respondents gave "C" letter grade level to Ethiopian broadcast journalists' media ethics violation. The case in EBC and SRTVA is worse where the media ethics violation boost up to " $\mathrm{B}+$ " letter grade level. This strengthen the first question result, there are significant, and even in certain cases critical, media ethics violations in the media.

\section{Conclusions and Recommendations}

\section{Conclusions}

The power of media can only serve public interests when practitioners are guided by media professional ethics. The professional codes of ethic basic principles are more universal although the practices are too national and situational. In the name of development journalism, practices of media ethics in Ethiopia are contextualized in a national level and designed with the behavior of the government. Ethiopian government officials usually level the western free press as "neoliberalist" and a tool serving to export "western ideology". They argued that the west media are also partisans and so it cannot be a model for Ethiopian media. The Ethiopian government media system and trend of practices are fixed deliberately with intention by the government; 
and it is required to serve in preaching government policies and strategies, success stories and achievements.

Media institutions should develop editorial policy documents to prevent their staffs from any deliberate and unconscious violation of principles which may lead to disciplinary action, potentially including dismissal. As such, the media observed in this research already developed editorial policy documents, except Sheger FM. The editorial documents seem a copy of the universal professional journalism codes of ethics, but there are a few phrases and paragraphs inserted which show a kind of shift from the universal angle and adjusted in away to serve the government interest. For instance, the watch dog role of media seems not welcomed; and public interest seems replaced by what the government likes to do to the public. The media are obsessed with attributing government officials, defending government claims and defaming anyone who speak what the government does not like to hear. Government statements are taken as fact and final, although, professional journalism demand for verification and balance from multiple sources depending on the issues of coverage.

Ethiopian government has designed Ethiopian press freedom proclamation- Proclamation No. 590/2008, and broadcasting proclamation- Proclamation No. 178/1999. Ethiopian Broadcast Authority (EBA) is the responsible government entity in dealing with media related issues. Both licensing and denying licenses are in the hands of EBA. Punishments on who violate such proclamations are imposed by the regular court. There is no popular media council who shares and takes any responsibility regarding media, journalists' as alternative to the regular court. There are a number of factors to influence journalists' job. Government officials, businessmen, PR practitioners and others approached the media with yellow-envelope for positive coverage than genuine. Because of such pulling factors and other pushing factors there was significant and sometimes critical violation of professional journalism ethics in the media. The external influences were paramount, specially, from government institutions, and officials. A few government officials assumed that the media are part of them and it should serve whatever they like to put on the media.

Ethiopian regional government media are the fruits of the incompact government federal system. The media are run by amateurs, mostly language and literatures graduates. For instance, 
about $(61 \%)$ of the selected media journalists are not graduates of journalism and communication. Even short trainings are available for only near to halves (49\%) of the journalists. The media contents are significantly loaded with art clips- music, drama, movies, poem, staged programs, artists' profile and interview and ads- than the hard core issues waving the country for centuries. This by itself contradicts with the philosophy of development journalism what the government media stand for. Development journalism doesn't advocate entertainment and commercialization over grass root news and voices.

One of professional journalists' qualities is passion and courage to their daily job. This can be derived from the interest and curiosity to be a journalist and to act ethically. About (70\%) of the selected media journalists indicated that they like to be a journalist; the rest $(30 \%)$ are working as journalist because they don't get alternatives jobs. Nearly (77\%) of the respondents join the media winning vacancy, but there were also journalists who were appointed directly by the government. The process of recruiting journalists needs thorough examination and competition on the bases of academic merit, talent and accepted criteria. But, this is not always happening in Ethiopia.

The highest percentage of the selected media journalists confirmed that there are significant media ethics violations in their media. In AMMA and in FBC 65 percent respondents; in EBC 50 percent respondents; in FM Sheger 67 percent respondents; in SRTVA 81 percent respondents and in ORTVA 78 percent of respondents indicated that media ethics violation is a reality.

\section{Recommendations}

There are gaps between the basic media ethics principles and the practices in Ethiopian broadcast media. Going ahead with the existing gaps leads to the worst media practices and the media remain not only useless but as one of the hurdles of nation development process. Government should make clear and limit its interactions with the media and the media should stand by itself- be guided by professional principles, and editorial policies. The media shall implement the following recommendations to improve its positive role.

$\checkmark$ The media should compile clear, easily accessible editorial policy; 
The process of recruiting journalists should be based on their academic merits and winning vacancy

$\checkmark$ School of journalism graduates should get appropriate place in the media.

$\checkmark$ Continuous short and medium trainings should be offered to journalists on duty; trainings may focus on media editorial policy, media ethics, production skills etc.

$\checkmark$ Media councils, journalists' professional associations in various categories like Ethiopian Broadcast Journalists Associations, Directors Associations, and Editors' Associations etc shall be established out of external influences.

$\checkmark$ The role and rule of government on media shall be limited. The media shall not go beyond identifying its favorable media philosophy to government owned media. Government shall appreciate media self regulation mechanisms, easing tough media laws, allow critics and observe patience to hear what it doesn't need to hear about.

$\checkmark$ Government communication affair offices' news releases shall be checked and verified before airing. Because, the purposes of journalism and public relation are quite different and balancing news is always important to build creditability.

$\checkmark$ Although, journalists' monthly salary, allowances and per-diem are a little better than other civil servants, they live under low living status. Economically poor media community may more concern how to win living than professional principles. They may not have the moral strength to refrain from rent seeking. It shall be improved. 


\section{References}

Africa Media Review. (1993). Media Use, Knowledge of World Affairs and Image of Nations among Nigerian Youth. African Council for Communication Education, 7(1).

Amhara Mass Media Agency Editorial Policy. (2011). Bahar Dar, Ethiopia.

BBC. (n. d). Duty-based Ethics (Deontological Ethics). Accessed from BBC.co/UK, July, 2015.

Batoche Books Limited. (2001). Utilitarianism: John Stuart Mill 1863. 52 Eby Street South. Kitchener, Ontario N2G 3L1.

Belsey, A., \& Chadwick, R. (1992). Ethical Issues in Journalism and the Media. Routledge, New York, USA. Retrieved from http://www.ebookstore.tandf.co.uk/.

Biagi, S. (2013). Media Impact: An Introduction to Mass Media. Enhanced (10 ${ }^{\text {th }}$ Ed.). Michael Rosenberg. Boston, USA.

Carpentier, N, Tomanić, I, Pille, P., et al. (2010). Media and Communication Studies Interventions and Intersections: The Intellectual Work of the 2010 ECREA European Media and Communication Doctoral Summer School, Tartu University Press.

Committee of Concerned Journalists. (2000). Individual Values, Social Pressures, and Conflicting Loyalties.

Cunningham, S. (1999). Journal of Mass Media Ethics: Getting It Right. Aristotle's "Golden Mean" as Theory Deterioration, 14(1), 5-15.

Danesi, M. (2009). Dictionary of Media and Communication. M.E. Sharpe, New York.

Dijk, A. (n. d). Power and the News Media, University of Amsterdam. Retrieved from http://www.daneprairie.com.

Ethiopian Broadcasting Corporation Editorial Policy. (July, 2014).

Ethiopian Broadcasting Proclamation: Proclamation No. 178/1999.

Ethiopian Press Freedom Proclamation: Proclamation NO. 590/2008.

Fana Broadcasting Corporate Editorial Policy. (2011).

Gangadharan, S. P., Cleen, B. De, \& Carpentier, N. (2007). Alternatives on Media Content, Journalism and Regulation. Tartu University Press.

Goldberg, D., Sutter, G., \& Walden, I. (2009). Media Law and Practices. Oxford University Press; New York, USA.

Lencho, N. (n, d). Communicating for Development and Democratization in Ethiopia: Journalistic Practices and Challenges. Addis Ababa University, Addis Ababa, Ethiopia.

Margolis, J. (2010). Media Law: Hand Book Series Edition. Bureau of International Information, United States Department of state. 
Moore, R. L., \& Murray, M. D. (2008). Media Law and Ethics. Taylor \& Francis eLibrary: New York London.

Napoli, P. M. (Winter 2014). Measuring Media Impact: an Overview of the Field. School of Communication \& Information. Rutgers University. Retrieved from www.learcenter.org.

Oromiya Radio and Television Agency Editorial Policy. (2010).

Pacific Journalism Review. (2005). Media Ethics and Accountability: A case study in ethical failure: Twenty Years of Media Coverage of Aboriginal deaths in custody.

Pater, D. (2006). Standards of Free Press: Journalism Text Book. USA Department of State. Translated to Amharic by Likemariam Demesie.

Reuters Handbook of Journalism. (February, 2012). Reuters Handbook of Journalism. Last modification 22:54, 24 November 2009. Accessed online August, 2015.

South Radio and Television Agency Editorial Policy. (2010).

Spilsbury, S. (2000). Media Law. Cavendish Publishing Limited. Great Britain, London. Retrieved from www.cavendishpublishing.com.

The New York Times. (2004). Ethical Journalism: A Handbook of Values and Practices for the News and Editorial Departments, New York.

White, A. (2008). The Ethical Journalism Initiative. International Press Centre Residence Palace Published in Belgium by Brussels Belgium. 